\section{Ozone-rich transients in the upper equatorial Atlantic troposphere}

\author{
K. Suhre ${ }^{\star}$, J.-P. Cammas ${ }^{\star}$, P. Nédelec ${ }^{\star}$, R. Rosset ${ }^{\star}$, \\ A. Marenco $*$ \& H. G. J. Smit $\dagger$ \\ * Laboratoire d'Aérologie (UMR CNRS/UPS 5560), OMP, 14, \\ Avenue Edouard Berlin, 31400 Toulouse, France \\ $\dagger$ Research Centre Jülich, Institute for Chemistry of the Polluted Atmosphere \\ (ICG-2), PO Box 1913, 52425 Jülich, Germany
}

High concentrations of ozone are found in the Earth's stratosphere, but strong stratification suppresses efficient exchange of this ozone-rich air with the underlying troposphere. Upward transport of tropospheric trace constituents occurs mainly through equatorial deep convective systems. In contrast, significant downward transport of ozone-rich stratospheric air is thought to take place only outside the tropics by exchange processes in upper-level fronts associated with strong distortions of the tropopause ${ }^{1}$. Ozone within the tropical troposphere is assumed to originate predominantly from ground-based emissions of ozone precursors, particularly from biomass burning ${ }^{2}$, rather than from a stratospheric source. Recent measurements of ozone in the upper troposphere in convective regions over the Pacific Ocean ${ }^{3}$ indeed reveal near-zero concentrations. Here we present sharply contrasting observations: ozone-rich (100-500 parts per billion by volume) transients were frequently encountered by specially equipped commercial aircraft at a cruising altitude of $10-12 \mathrm{~km}$ (in the upper troposphere) in the vicinity of strong convective activity over the equatorial Atlantic Ocean. This strongly suggests that the input of stratospheric ozone into the troposphere can take place in the tropics. We suggest that this transport occurs either by direct downward movement of air masses or by quasi-isentropic transport from the extratropical stratosphere.

Five commercial Airbus 340 aircraft operated by Air France, Austrian Airlines and Lufthansa have been equipped with ozone, temperature and humidity instruments, as part of the 'Measurement of Ozone by Airbus In-Service Aircraft' (MOZAIC) project ${ }^{4,5}$. We report here an analysis of more than 100 flights across the InterTropical Convergence Zone (ITCZ) over the tropical Atlantic Ocean between Europe and South America. During most of the Atlantic transect, ozone mixing ratios are well below 50 parts per billion by volume (p.p.b.v.) with only small fluctuations. But in one-third of the reported flights, uniquely within the $15^{\circ} \mathrm{N}-15^{\circ} \mathrm{S}$ equatorial latitude belt, we observe events where ozone mixing ratios suddenly increase for a short time period to over 100 p.p.b.v., and in some cases up to 500 p.p.b.v., at a horizontal scale of $5-80 \mathrm{~km}$. A representative example is shown in Figs 1 and 2. At the same time, the aircraft enters a zone of turbulence of about the same horizontal extent, as the pressure-altitude records indicate a vertical displacement of the order of $10 \mathrm{~m}$ (Fig. 1d) and abrupt changes in wind speed and direction are observed (Fig 1e, f). At the same time as these high-ozone events, water mixing ratios usually increase drastically (Fig. 1b) and temperatures slightly decrease (Fig. 1c), but not systematically for the latter. Relative humidity $>100 \%$ is sometimes observed during MOZAIC flights and particularly during these high-ozone events. This is not ascribed to artefacts; the extra water is probably provided by the evaporation of water droplets due to adiabatic compression and associated heating which cause a substantial temperature increase in the humiditysensor housing at cruising speeds of Mach 0.8. Thus, the high humidity values must be interpreted qualitatively as indicating the presence of ice crystals during the sampling. The aircraft often deviates from its otherwise straight flight track during these highozone events, apparently to outflank an equatorial convective system. The presence of active deep convection has been identified on NOAA/AVHRR satellite images in most cases. Note that for safety reasons passenger aircraft never pass through the active part of tropical deep convective systems, but at a distance of $15-30 \mathrm{~km}$ around the convective cloud towers, thus passing under the anvil clouds and their precipitation streaks.

In $10 \%$ of all analysed flights across the ITCZ, an event with very high ozone mixing ratio ( $>150$ p.p.b.v.) over a distance of some tens of kilometres has been observed, together with all the following: turbulence, decreasing temperature, rising humidity, changes in wind speed and direction, deviation of the aircraft trajectory from a straight line, and convective systems on NOAA/AVHRR images. In even more cases (30\% of all flights), high ozone values (100200 p.p.b.v.) have been found and correlated with some, but not always all, of the observations described above. These latter cases are likely to be the observation of residual perturbations some time after the event itself occurred, whereas the $10 \%$ of 'full' cases probably represent observations that took place shortly after the perturbations were caused. Here we consider only observations of 'full' cases made over the Atlantic Ocean, where MOZAIC data is most dense.

More than 5,000 MOZAIC flights in the upper troposphere (lowozone regime) as well as in the lower stratosphere (high-ozone regime) show that the performance of the ozone analyser is not affected by the aircraft entering or leaving clouds (no significant ozone changes are observed), by turbulence (many cases of strong turbulence without change in ozone concentrations have been observed outside the tropics), or by icing of the ozone inlet (no significant changes of flow rates in the sampling line and ozone device have been observed). The rare erratic ozone values that are sometimes found consist in the worst case of only two successive records. On a large number of MOZAIC flights to South Africa and to Asia similar cases of high-ozone transients have been encountered when crossing the ITCZ, but never in middle latitudes. On one occasion one aircraft encountered the same ozone transient twice: on its flight towards Bangkok and again when heading back to Paris several hours later. On another occasion, two different aircraft flying from South America towards Europe sampled the same ozone transient within a 30 minute interval and at a horizontal separation of $10 \mathrm{~km}$. Measurement artefacts can therefore be ruled out as a possible cause for the high ozone mixing ratios.

On a spatial scale the observed events are small $(5-80 \mathrm{~km})$ and sharply marked. The proximity of the observed high-ozone values to equatorial deep convective systems, as indicated by aircraft deviations, turbulence, satellite images and humidity measurements (indicating the presence of ice particles), suggest that the observed phenomena are linked to these convective systems. We can exclude any local surface sources and orography-induced vertical transport as all selected events occur over the open ocean. In the free troposphere photochemically produced ozone, even in plumes from biomass burning, never exceeds levels of 100-150 p.p.b.v. (refs 6, 7). Cloud-charging processes caused by the dynamics in heavy cumulonimbus clouds can be a local source of ozone ${ }^{8}$ : here ozone is produced by point discharges from water droplets in intense electrical fields ${ }^{9}$ or by electrical discharging of a lightning flash ${ }^{10}$. In some field experiments in the vicinity of electrified clouds, highozone transients have been observed in the lower troposphere ${ }^{10,11}$. If the ozone transients observed during MOZAIC flights originate from discharging processes in cumulonimbus clouds, then the ozone is probably produced in the core of these clouds while the aircraft is flying outside the core in the divergence zone of the deep convective region. The ozone would then originate from air masses being detrained from the upward-moving convective flow. At present it is not clear if the dynamics within the observed deep 

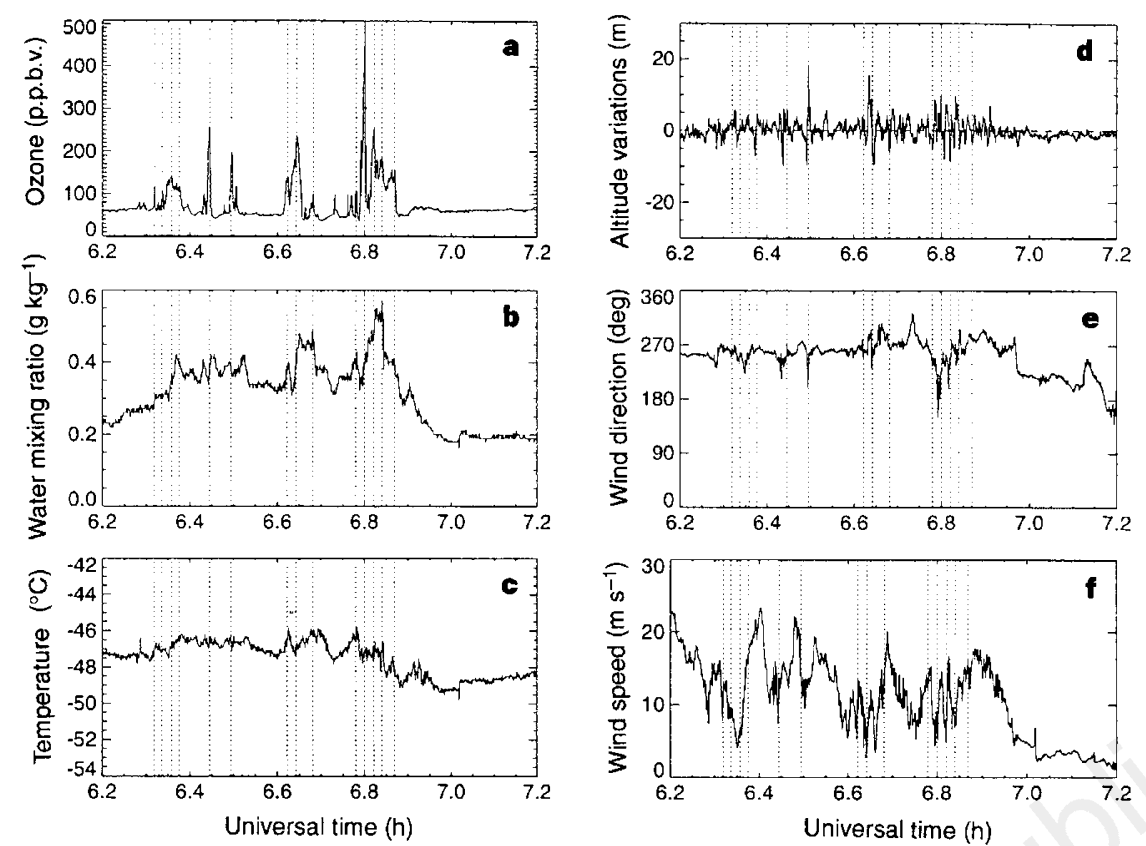

Figure 1 Time series of: a, ozone mixing ratio; b, water vapour mixing ratio; c, temperature; d, barometric flight altitude variations; e, wind direction; $\mathbf{f}$, wind speed. These time series were measured on MOZAIC flight Paris-São Paulo on 21 November 1994. The time of the encounter of ozone maxima are marked by vertical dashed lines on all graphs. This time series represents one hour of measurements during which the aircraft travelled $860 \mathrm{~km}$ from $7^{\circ} 20^{\prime} \mathrm{N}, 27^{\circ} 20^{\prime} \mathrm{W}$ to $0^{\circ} 30^{\prime} \mathrm{N}, 30^{\circ} 20^{\prime} \mathrm{W}$. (data acquisition every $4 \mathrm{~s}$, resulting in a spatial resolution of about $1 \mathrm{~km}$ ). Before and after the event shown here, ozone mixing ratios were always well below 100 p.p.b.v. in tropical latitudes. Instrumentation was as follows: a, a dual-beam ultraviolet absorption instrument, Thermo-Electron model 49-103 (detection limit 2 p.p.b.v., overall precision $\pm 2 \%$ ); $\boldsymbol{b}$ and $\mathbf{c}$, an AERODATA AD-F8-88 instrument installed in a Rosemount housing; d, e, f, Airbus A340 on-board instruments. Documentation of ten representative cases is available on the ftp site ftpaero.aero. obs-mip.fr (file: /pub/salsa/mozaic/SUPP1.PS).

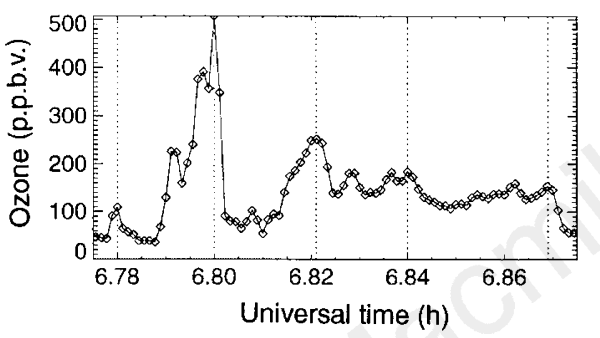

convective clouds encountered concurrently with the observed ozone transients during the MOZAIC flights were sufficiently strong to induce cloud-charging processes with electric fields high enough to produce significant amounts of ozone.

An alternative and more likely explanation for our observations is that the high ozone mixing ratios have a stratospheric origin. Direct vertical downward transport could, for example, move ozone-rich air from the equatorial stratosphere into the upper troposphere. Recent measurements ${ }^{12,13}$ show that ozone mixing ratios high enough to cause the ozone transients measured by the aircraft occur in mixed layers formed by tropical cumulus anvil outflow ${ }^{14}$ in the stratosphere at about $18 \mathrm{~km}$ altitude. The observation of overshoots of cumulonimbus tops into the stratosphere ${ }^{15-17}$ provides further evidence that the entrainment of stratospheric air into an anvil outflow is dynamically possible. Precipitation streaks loaded with ice particles falling from the anvil ${ }^{18-20}$ can then transport ozone-rich air through the tropopause region into the upper troposphere. Further evaporative cooling and stronger downdrafts ${ }^{21}$ may then move the air rapidly down to the aircraft's flight level at $10-12 \mathrm{~km}$ altitude. This mechanism requires continuous evaporative cooling to reduce the potential temperature of the air parcel from its originally high stratospheric value of $\sim 400 \mathrm{~K}$ to $\sim 340$ $350 \mathrm{~K}$ at flight level. This can only be achieved by a continuous supply of ice particles growing in the anvil outflow, as proposed in Danielsen's stratospheric dehydration mechanism ${ }^{18,19}$ with the largest particles falling close to the anvil outflow into the descending air parcel. The precise dynamical mechanism of that ozone downward transport still has to be established, and certainly needs more detailed sensing of the upper part of convective systems than available in the MOZAIC project. Another mechanism for vertical downward transport of stratospheric air into the troposphere has
Figure 2 Expanded-scale view of part of the ozone time series in Fig. 1a. Data points, represented by diamonds, are recorded every $4 \mathrm{~s}$ which corresponds to a horizontal resolution of $\sim 1 \mathrm{~km}$. The locationof the aircraft at the middle of this time series was approximately $3^{\circ} 0^{\prime} \mathrm{N}, 28^{\circ} 50^{\prime} \mathrm{W}$. been proposed by Newell et al. ${ }^{22}$. Although this process operates on much larger horizontal and temporal scales, it might play an initiating role in transferring stratospheric air several kilometres downwards before the actual convective event moves it down to flight level.

Instead of tracing their origin in the equatorial stratosphere, the observed ozone transients could also be the result of horizontal transport of ozone-rich air from the extratropical stratosphere followed by vertical convective transport to flight level. The central Atlantic, being downstream of the eastern major trough over the United States and at the tail end of the corresponding storm tracks, is a favoured region of extratropical wave-breaking far equatorward of the subtropical jet stream. Fragmentation of extratropical stratospheric-air intrusions ${ }^{23}$ into elongated $(2,000-3,000 \mathrm{~km})$ and slender $(200 \mathrm{~km})$ streamers could be consistent with MOZAIC observations. This quasi-isentropic mechanism does not require cooling of the transported air mass (the 340-350 K isentropic layer in the middle latitudes is situated in the lower stratosphere where ozone mixing ratios are as high as those observed in the transients), but it is not yet clear whether thin streamers can extend into the equatorial region without undergoing significant mixing with tropospheric air. Meridional cross-sections of a climatologically averaged height of the $340-350 \mathrm{~K}$ isentropic layer indicate that the MOZAIC aircraft fly below this layer in the subtropics and enter it only in the equatorial latitude belt, in agreement with the observed locations of the ozone transients. Newell et al. ${ }^{24}$ and Browell et al. ${ }^{25}$ report ozone layers of stratospheric origin in the upper tropical troposphere, but with maximum ozone mixing ratios well below 100 p.b.b.v. The difficulty in determining whether this mechanism is at the origin of the observed ozone transients is that in such a long-range isentropic transport the air gradually loses its original 
stratospheric characteristics by radiative processes (which act on the temperature and hence the potential vorticity). Although this air may keep its initial chemical composition, the loss of its stratosphere characteristics makes it difficult to distinguish from tropospheric air when using basic weather analysis charts.

The ozone transients encountered relatively often on the reported MOZAIC flights is a new finding that contrasts strongly with the near-zero ozone concentrations in about the same part of the upper troposphere observed by Kley et al. ${ }^{3}$, emphasizing the enormous variability of equatorial tropospheric ozone concentrations. We have put forward three possible explanations of the observed phenomena, without however being able to decide between them on the basis of current knowledge. Formation of ozone by cloudcharging processes at the observed scale $(5-80 \mathrm{~km})$ in the upper troposphere has so far not been observed, favouring a dynamical explanation. The possible existence of a mechanism of transport of stratospheric air into the upper equatorial troposphere is most intriguing and reflects our still poor knowledge of the dynamics of the upper part of the equatorial troposphere, particularly with regard to mass transfer between stratosphere and troposphere during deep convection and extratropical baroclinic wave-breaking extending into the equatorial belt. Furthermore, the existence of the ozone transients implies that the ozone budget of the equatorial troposphere is less well understood than has been assumed.

Received 24 March; accepted 19 June 1997.

1. Holton, J. R. et al. Stratosphere-troposphere exchange. Rev. Geophys. 33, 403-439 (1995)

2. Crutzen, P. J., Heidt, L. E., Krasnec, J. P., Polloc, W. H. \& Seiler, W. Biomass burning as a source of atmospheric trace gases $\mathrm{CO}, \mathrm{H}_{2}, \mathrm{~N}_{2} \mathrm{O}, \mathrm{NO}, \mathrm{CH}_{3} \mathrm{Cl}$ and COS. Nature 282, 253-356 (1979).

. Kley, D. et al. Observations of near-zero ozone concentrations over the convective Pacific: effects on air chemistry. Science 274, 230-233 (1996).

4. Marenco, A., Nedelec, P., Thouret, V. \& Grouhel, C. in DLR-Mitteilungen (eds Schumann, U. \& Wurzel, D.) 94-06, 26-31 (DLR, Ober Pfaffen Hofen, 1994).

5. Marenco, A. The MOZAIC programme. EUROTRAC Newsl. 17, 2-7 (1996).

6. Andreae, M. O. et al. Influence of plumes from biomass burning on atmospheric chemistry over the equatorial and tropical South Atlantic during CITE-3. J. Geophys. Res. 99, 12793-12809 (1994).

7. Delany, A. C., Haagensen, P., Walters, S., Wartburg, A. F. \& Crutzen, P. J. Photochemically produced ozone in the emissions from large-scale tropical vegetation fires. J. Geophys. Res. 90, 2425-2429 (1985).

8. Griffing, G. W. Ozone and oxides of nitrogen production during thunderstorms. J. Geophys. Res. 82, 943-950 (1977)

9. Shlanta, A. \& Moore, C. B. Ozone and point discharge measurements under thunderstorms. J. Geophys. Res. 77, 4500-4510 (1972).

10. Orville, R. E. Ozone production during thunderstorms, measured by the absorption of ultraviolet radiation from lightning. J. Geophys. Res. 72, 3557-3561 (1967).

11. Clarke, J. F. \& Griffing, G. W. Aircraft observations of extreme ozone concentrations near thunderstorms. Atmos. Environ. 19, 1175-1179 (1985).

12. Vömel, H., Oltmans, S. J., Kley, D. \& Crutzen, P. J. New evidence for the stratospheric dehydration mechanism in the equatorial Pacific. Geophys. Res. Lett. 22, 3235-3238 (1995).

13. Russel, P. B., Pfister, L. \& Selkirk, H. B. The tropical experiment of the stratosphere-troposphere exchange project (STEP): science objectives, operations, and summary findings. J. Geophys. Res. 98 8563-8589 (1993)

14. Lilly, D. K. Cirrus outflow dynamics. J. Atmos. Sci. 45, 1594-1605 (1988).

15. Roach, W. T. On the nature of the summit areas of severe storms in Oklahoma. Q. J. R. Meteorol. Soc 93, 318-336 (1967).

16. Burnham, J. Atmospheric gusts - a review of the results of some recent research at the royal aircraft establishment. Mon. Weath. Rev. 98, 723-734 (1970).

17. Cornford, S. G. \& Spavins, C. S. Some measurements of cumulonimbus tops in the pre-monsoon season in north-east India. Meteorol. Mag 102, 314-332 (1973).

18. Danielsen, E. F. A dehydration mechanism for the stratosphere. Geophys. Res. Lett. 9, 605-608 (1982).

19. Danielsen, E. F. In situ evidence of rapid, vertical, irreversible transport of lower tropospheric air into the lower tropical stratosphere by convective cloud turrets and by large-scale upwelling in tropical cyclones. J. Geophys. Res. 98, 8665-8681 (1993).

20. Knollenberg, R. G., Kelly, K. \& Wilson, J. C. Measurements of high number densities of ice crystals in the tops of tropical cumulonibus. J. Geophys. Res. 98, 8639-8664 (1993).

21. Sun, J., Braun, S., Biggerstaff, M. I., Fovell, R. G. \& Houze, R. A. Jr Warm upper-level downdrafts associated with a squall line. Mon. Weath. Rev. 121, 2919-2927 (1993).

22. Newell, R. E., Zhu, Y., Browell, E. V., Read, W. G. \& Waters, J. W. Walker circulation and tropical upper tropospheric water vapor. J. Geophys. Res. 101, 1961-1974 (1996).

23. Appenzeller, C., Davies, H. C. \& Norton, W. A. Fragmentation of stratospheric intrusions. J. Geophys. Res. 101, 1435-1456 (1996)

24. Newell, R. E. et al. Vertical fine-scale atmospheric structure measured from NASA DC-8 during PEMWest A. J. Geophys. Res. 101, 1943-1960 (1996).

25. Browell, E. V. et al. Large-scale air mass characteristics observed over Western Pacific during summertime. J. Geophys. Res. 101, 1691-1712 (1996)

Acknowledgements. We thank Air France A340 pilot De Boysson for eye-witness information from MOZAIC flights in the tropics; we also acknowledge discussions with many of our colleagues. On behalf of the MOZAIC programme, we thank Air France, Lufthansa, Austrian Airlines and Sabena, who agreed to carry the MOZAIC equipment free of charge. This work was supported by the European Commission DG XII and Centre National de la Recherche Scientifique (CNRS-INSU); satellite images were made available by NOAA-SAA.

Correspondence should be addressed to K.S. (e-mail: suhk@aero.obs-mip.fr). Additional information on the MOZAIC programme is available on http://www.cnrm.meteo.fr:8000/mozaic/

\section{Conspecific sperm precedence in Drosophila}

\section{Catherine S. C. Price}

Department of Ecology and Evolution, University of Chicago, 1101 East 57th Street, Chicago, Illinois 60637, USA

Traits that influence the interactions between males and females can evolve very rapidly through sexual selection ${ }^{1}$ or sexually antagonistic coevolution ${ }^{2}$. Rapid change in the fertilization systems of independent populations can give rise to reproductive incompatibilities between population $s^{3,4}$, and may contribute to speciation $^{5}$. Here I provide evidence for cryptic reproductive divergence among three sibling species of Drosophila that leads to a form of postmating isolation. When a female mates with both a conspecific and a heterospecific male, the conspecific sperm fertilize the vast majority of the eggs, regardless of the order of the matings. Heterospecific sperm fertilize fewer eggs after these double matings than after single matings. Experiments using spermless males show that the seminal fluid of the conspecific male is largely responsible for this conspecific sperm precedence. Moreover, when two males of the same species mate sequentially with a female from a different species, a highly variable pattern of sperm precedence replaces the second-male sperm precedence that is consistently found within species. These results indicate that females mediate sperm competition, and that second-male sperm precedence is not an automatic consequence of the mechanics of sperm storage.

Whenever a female mates with more than one male during a single fertile period, the opportunity for sperm competition is created $^{6}$. A male's fitness on mating will be greatly influenced by his ability to interfere with resident sperm or to defend his sperm against interference by subsequent males. Male traits affecting sperm competition are therefore expected to be under strong selection. Female fitness is also influenced by multiple mating ${ }^{7}$, and females can be directly harmed by male adaptations for sperm competition $^{8}$, so females should be under strong selection to mediate sperm competition. Such strong selection sets up the opportunity for rapid divergence among populations in traits that influence sperm competition. Nevertheless, the possibility of competition-dependent postmating, prezygotic reproductive isolation has not to my knowledge been investigated in organisms in which sperm competition has been extensively studied, such as Drosophila.

Conspecific sperm precedence (CSP) has been documented previously in grasshoppers ${ }^{9,10}$, crickets $^{11}$ and flour beetles ${ }^{12}$. It is not known, however, whether the reproductive isolation described in these species is strictly dependent upon sperm competition, as none of these studies directly compared the number of hybrids produced after a single observed heterospecific copulation with the number produced after one heterospecific and one conspecific copulation. Here I show that conspecific sperm preference among three species of Drosophila is a form of reproductive isolation that becomes apparent only after multiple matings, and is produced in large part by the seminal fluid of the conspecific male. Moreover, two independent experiments indicate that there is divergence among these species in traits that influence sperm competition.

The common outcome of sperm competition within most species of insects and birds is second-male precedence ${ }^{13}$. In Drosophila, females of many species mate with multiple males in nature, and in the laboratory the second male to mate typically fathers at least $85 \%$ of the offspring ${ }^{14}$. Although the mechanisms of sperm precedence in Drosophila remain unknown, the phenomenon appears to be influenced in large part by the seminal fluid of the second male ${ }^{15}$. 